\title{
Collision debris yields five-quark particle
}

\section{David Cyranoski, Tokyo}

A class of subatomic particle, consisting of five quarks rather than the normal two or three, has been discovered by physicists in Japan. Theorists had expected combinations of four or more to exist, but experiments over the past 30 years had failed to detect them.

A team from the SPring-8 synchrotron in Harima, near Kobe, created the particles by firing $\gamma$-rays at a carbon target. The researchers, led by Takashi Nakano of Osaka University's Research Center for Nuclear Physics, say that the five-quark particle probably formed when two particles - a neutron, which is made up of three quarks, and a $\mathrm{K}+$ meson, which contains two fused during the collision. Evidence of the particle, which decayed rapidly, was found by analysing debris from the collision.

The discovery, which is due to be published on 4 July in Physical Review Letters, will give a huge boost to particle-physics research, and could have important implications for our understanding of the early Universe.

Nakano himself might never have thought to look for the five-quark particle had it not been for a series of lunchtime conversations with Dmitri Diakonov of the Nordic Institute for Theoretical Physics in Copenhagen, while the pair attended a conference in 2000. Diakonov thought that the experiments that Nakano was planning could produce a five-quark particle, and suggested a new data-analysis method that he argued would reveal the particle's presence. "Dmitri suggested that the particle could exist as a smaller particle at a lower energy level, so that's where we looked," says Nakano.

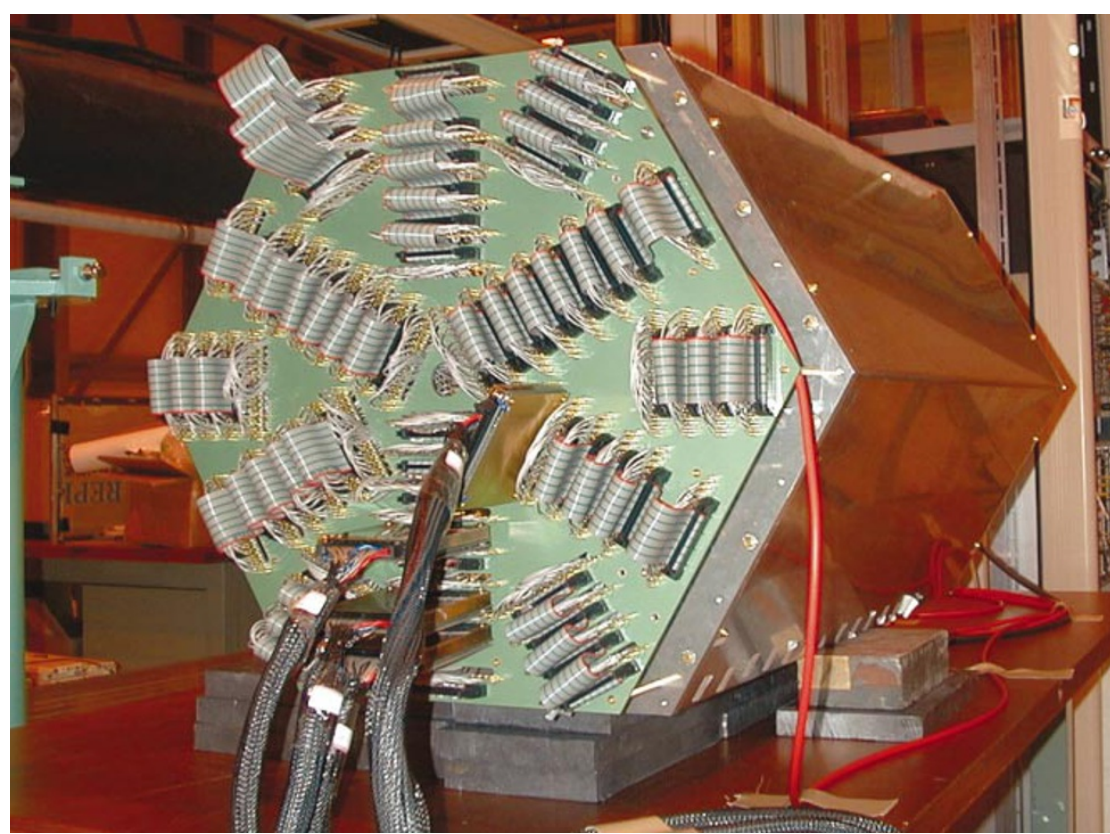

The time-projection chamber at SPring-8, which played a role in the quest to find a five-quark particle.

"It was a novel way of interpreting the data."

Nakano presented his findings last October at the International Conference on Particles and Nuclei in Osaka. "We got a pretty negative response," he says. "Most people thought it was impossible." But in the months after the conference, a group at the Thomas Jefferson National Accelerator Facility in Newport News, Virginia, confirmed Nakano's results by revisiting data from previous experiments. The group presented its data, now submitted for publication, at the Conference on the Intersection of Nuclear and Particle Physics, held in New York in May.

Nakano says that the discovery could help to pin down some theories of the early Universe - such as how quarks came together to form matter after the Big Bang. "Studies on two- and three-quark matter had hit a wall," he says. "This might provide more clues."

But he adds that the five-quark particles are not likely to be found in many places in today's Universe. "It's very unlikely that these exist anywhere freely, except maybe in a black hole," says Nakano.

\section{0xford professor accused of discrimination over e-mail}

Haim Watzman, Jerusalem

A pathologist at the University of Oxford is facing an internal inquiry after he refused an Israeli student's $\mathrm{PhD}$ application because the student had served in Israel's army.

The student, Amit Duvshani, is currently studying in the medical faculty of Tel Aviv University. He sent a letter and curriculum vitae to Andrew Wilkie of Oxford's Weatherall Institute of Molecular Medicine because he was interested in Wilkie's research field of birth defects in embryos.

Wilkie responded by e-mail, advising Duvshani in no uncertain terms to look elsewhere. "I have a huge problem with the way that the Israelis take the moral high ground from their appalling treatment in the Holocaust, and then inflict gross human rights abuses on the Palestinians because they (the Palestinians) wish to live in their own country," he wrote, adding: "I am sure that you are perfectly nice at a personal level, but no way would I take on somebody who had served in the Israeli army."

Duvshani shared the e-mail among students and faculty members in the medical school, who in turn circulated it more widely to scientists and news organizers - prompting outrage at what many see as overt discrimination against a student from a country where most young people are conscripted to serve in the military. Several angry protests were made directly to Wilkie, and to the University of Oxford.

Wilkie has issued an apology, which was posted on the university's website on 27 June. "I recognise and apologise for any distress caused by my e mail of 23 June and the wholly inappropriate expression of my personal opinions in that document," he wrote. Duvshani says that Wilkie subsequently contacted him personally, seeking his reaction to the incident.

The University of Oxford issued a statement announcing an internal investigation, which a spokesman says will be completed this week. "Freedom of expression is a fundamental tenet of university life," the statement said, "but under no circumstances are we prepared to accept or condone conduct that appears to, or does, discriminate against anyone on grounds of ethnicity or nationality, whether directly or indirectly." 